\title{
Reduced plasma concentration of branched-chain amino acids in sarcopenic older subjects: a cross-sectional study
}

\author{
Inger Ottestad $^{1 *}$, Stine M. Ulven ${ }^{1,2}$, Linn K. L. Øyri ${ }^{1,3}$, Kristin S. Sandvei ${ }^{1}$, Gyrd O. Gjevestad $^{1,4}$, \\ Asta Bye ${ }^{2,5}$, Navida A. Sheikh ${ }^{2} \dagger$, Anne S. Biong ${ }^{4}$, Lene F. Andersen ${ }^{1}$ and Kirsten B. Holven ${ }^{1,3}$ \\ ${ }^{1}$ Department of Nutrition, Institute of Basic Medical Sciences, University of Oslo, PO Box 1046, Blindern, O317 Oslo, Norway \\ ${ }^{2}$ Department of Nursing and Health Promotion, Faculty of Health Sciences, Oslo and Akershus University College of Applied \\ Sciences, PO Box 4, St. Olavs plass, 0130 Oslo, Norway \\ ${ }^{3}$ National Advisory Unit on Familial Hypercholesterolemia, Department of Endocrinology, Morbid Obesity and Preventive \\ Medicine, Oslo University Hospital, 0373 Oslo, Norway \\ ${ }^{4}$ Centre for Research and Development, TINE SA, PO Box 7, Kalbakken, 0902 Oslo, Norway \\ ${ }^{5}$ Regional Advisory Unit for Palliative Care, Department of Oncology, Oslo University Hospital, PO Box 4950 Nydalen, O424 \\ Oslo, Norway
}

(Submitted 20 September 2017 - Final revision received 23 March 2018 - Accepted 18 April 2018 - First published online 18 June 2018)

\section{Abstract}

Branched-chain amino acids (BCAA) are essential amino acids that are necessary for muscle mass maintenance. Little is known about the plasma concentrations of BCAA and the protein intake in relation to sarcopenia. We aimed to compare the non-fasting plasma concentrations of the BCAA and the dietary protein intake between sarcopenic and non-sarcopenic older adults. Norwegian older home-dwelling adults $(\geq 70$ years) were invited to a cross-sectional study with no other exclusion criteria than age. Sarcopenic subjects were defined by the diagnostic criteria by the European Working Group on Sarcopenia in Older People. Non-fasting plasma concentrations of eight amino acids were quantified using NMR spectroscopy. Protein intake was assessed using $2 \times 24$-h dietary recalls. In this study, ninety out of 417 subjects ( $22 \%$ ) were sarcopenic, and more women $(32 \%)$ than men $(11 \%)$ were sarcopenic $(P<0 \cdot 0001)$. Sex-adjusted non-fasting plasma concentrations of leucine and isoleucine, and the absolute intake of protein $(\mathrm{g} / \mathrm{d})$, were significantly lower among the sarcopenic subjects, when compared with non-sarcopenic subjects $(P=0.003, P=0.026$ and $P=0.003$, respectively). A similar protein intake was observed in the two groups when adjusted for body weight (BW) and sex $(1.1 \mathrm{~g}$ protein $/ \mathrm{kg} \mathrm{BW}$ per $\mathrm{d} ; P=0.50)$. We show that sarcopenia is associated with reduced non-fasting plasma concentration of the BCAA leucine and isoleucine, and lower absolute intake of protein. More studies are needed to clarify the clinical relevance of these findings, related to maintenance of muscle mass and prevention of sarcopenia.

Key words: Sarcopenia: Branched-chain amino acids: Leucine: Protein intakes: Elderly

Age-related decline in muscle mass and strength (sarcopenia) is associated with impaired independence and poor quality of life, as well as increased morbidity and all-cause mortality risk ${ }^{(1-5)}$. The mechanisms of sarcopenia are most likely multi-factorial, in which low protein intake is among the suggested underlying causes $^{(6-11)}$.

High-quality proteins contain branched-chain amino acids (BCAA; leucine, isoleucine and valine), which are not synthesised in the human body. A postprandial increase in BCAA has been observed, leading to a rapid increase of plasma BCAA and uptake into muscle tissue $\mathrm{e}^{(12-15)}$. Intramuscular concentration of BCAA, particularly leucine, stimulates the muscle protein synthesis, as well as decreases muscle protein breakdown, and an anabolic response occurs when the synthesis exceeds the breakdown ${ }^{(16-22)}$.
Increased availability of amino acids when ingested, infused or from increased protein intake has been shown to stimulate the muscle protein synthesis, and a positive linear relationship between essential amino acids intake and the anabolic response has been suggested ${ }^{(20,22-24)}$. In addition, positive associations between serum concentrations of leucine, isoleucine and valine, and other metabolites of BCAA and both thigh muscle crosssectional area and fat-free mass index, have been observed in functionally limited older adults ${ }^{(25)}$. Further, plasma concentrations of the BCAA have been shown to be elevated $12 \mathrm{~h}$ after a high- $v$. low-protein meal ${ }^{(15)}$. Available data on blood concentration of BCAA in relation to sarcopenia are limited.

In a systematic review including forty-six studies among community-dwelling older adults (mean age $\geq 65$ years), in

Abbreviations: BCAA, branched-chain amino acids; BW, body weight; SM, skeletal muscle; SMI, skeletal muscle mass index.

* Corresponding author: I. Ottestad, email inger.ottestad@medisin.uio.no

$\dagger$ Department of Nutrition, Institute of Basic Medical Sciences, University of Oslo, PO Box 1046, Blindern, 0317 Oslo, Norway. 
which twenty-one studies were national nutrition surveys, it was shown that $10-12 \%$ did not meet the estimated average requirement for protein of $0.66 \mathrm{~g} / \mathrm{kg}$ body weight $(\mathrm{BW})$ per $\mathrm{d}^{(26)}$. Little is known about the protein intake among sarcopenic subjects $^{(4,9,27)}$. The aim of the present study was to compare the non-fasting plasma concentrations of the BCAA and the dietary protein intake between sarcopenic and non-sarcopenic home-dwelling older adults.

\section{Methods}

\section{Participants}

The present study was conducted from August 2014 to July 2015 at Oslo and Akershus University College of Applied Sciences, Norway. Invitation letters were sent to men and women ( $\geq 70$ years) living in the area of Skedsmo, Norway, and listed in the National Population Register. It was stated in the invitation letter that all subjects should meet for one visit, and they were informed that eligible subjects could be asked to participate in another study, a randomised trial (RCT) that aimed to study the effect of proteinenriched milk on muscle mass and strength. Thus, the present cross-sectional study also served as a screening visit for the RCT (Clinicaltrials.gov, ID no. NCT02218333) $^{(28)}$. There were no other exclusion criteria for participation than age. A total of 2820 subjects were invited, 477 (17\%) responded to the invitation and 438 (16\%) met for participation. One subject withdrew the informed consent and body composition was not assessed in twenty subjects, mainly owing to the use of pacemaker. Thus, 417 subjects were included in this cross-sectional study. The flow chart for recruitment and inclusion in the final analysis is shown in Fig. 1.
This study was conducted according to the guidelines laid down in the Declaration of Helsinki, and all procedures involving human subjects were approved by the Regional Committees for Medical and Health Research Ethics, Health Region South East, Norway (2014/150/REK). Written informed consent was obtained from all participants. Extracts from the National Population Registry were used according to, and with approval from, the Norwegian Tax Administration.

\section{Assessment of sarcopenia, cognitive health and malnutrition}

The suggested diagnostic criteria and cut-off points by the European Working Group on Sarcopenia in Older People (EWGSOP) were used to identify subjects with both low muscle mass and low muscle strength and/or physical performance (sarcopenia) ${ }^{(7)}$. Height $(\mathrm{cm})$ was measured using the Harpenden Stadiometer (Holtain Ltd). A Tanita 100 bioimpedance analyser (BIA) (BC-418; Tanita Corp.) and the regression equation by Janssen et al. were used to assess skeletal muscle (SM) mass $\left(\mathrm{SM}=\left(\left(\mathrm{Ht}^{2} / \mathrm{R} \times\right.\right.\right.$ $0 \cdot 401)+(\operatorname{sex} \times 3.825)+(\operatorname{age} \times-0.71))+5.102$, where Ht is height $(\mathrm{cm}), \mathrm{R}$ is BIA resistance $(\Omega)$, for sex, men $=1$ and women $=0$, and age in years were used ${ }^{(29)}$. Further, skeletal muscle mass index (SMI) was defined as SM ( $\mathrm{kg}) /$ height $\left(\mathrm{m}^{2}\right)$, and was used to identify subjects with reduced muscle mass ${ }^{(7)}$. According to EWGSOP, subjects with SMI $<8.87 \mathrm{~kg} / \mathrm{m}^{2}$ and $<6.42 \mathrm{~kg} / \mathrm{m}^{2}$ in men and women, respectively, were categorised as subjects with reduced

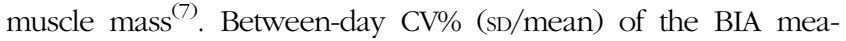
surement of fat-free mass was calculated in a subgroup ( $n$ 46). Each subject was measured twice, on separate days. The betweenday CV\% was $1 \cdot 8$.

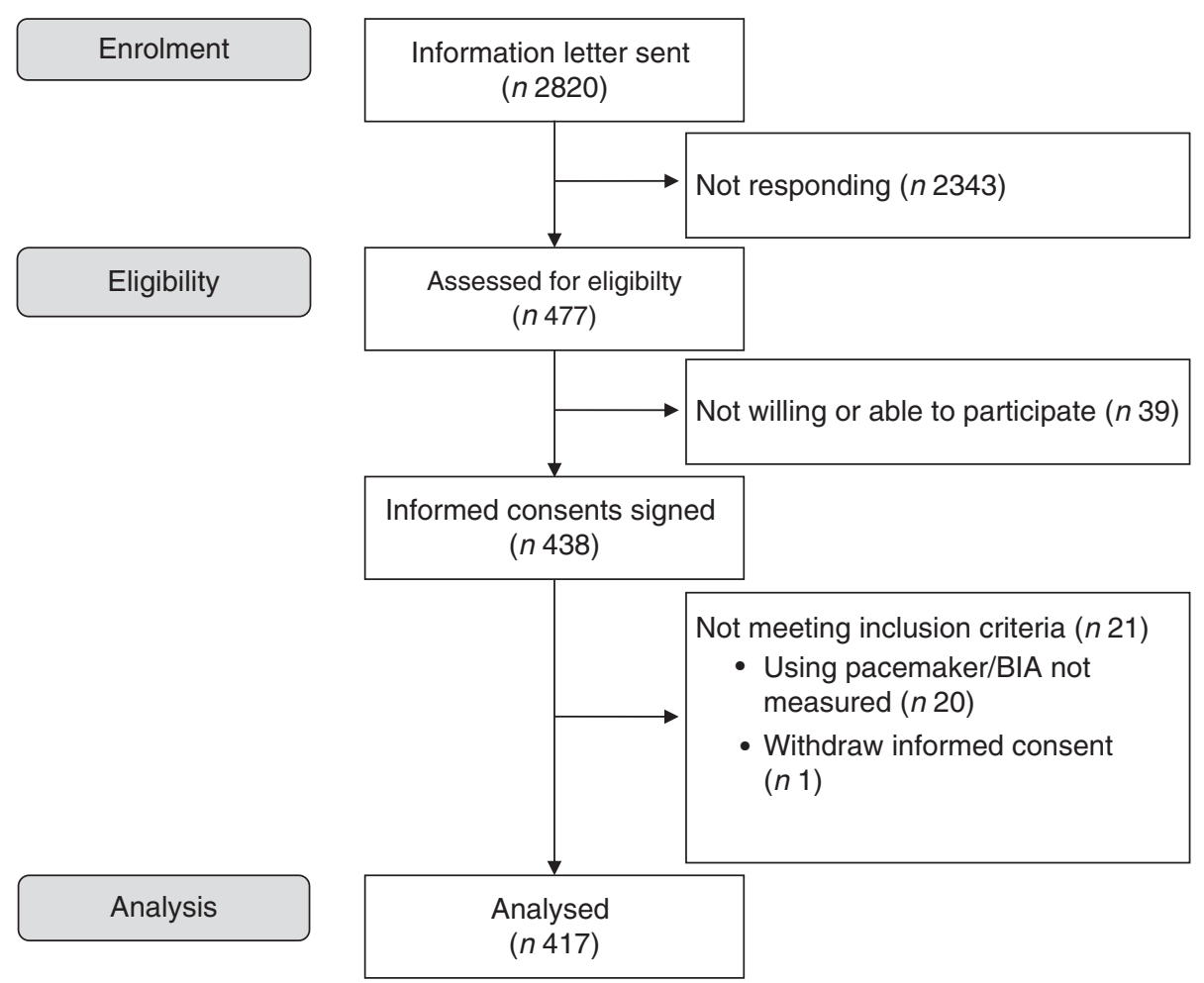

Fig. 1. Flow chart of the study participants. BIA, bioimpedance analyser. 
Handgrip strength of both hands was measured, using a digital handheld dynamometer (KE-MAP80K1; Kern Map). The maximum handgrip strength of three measurements from each hand was registered, and reduced handgrip strength was defined as $<20 \mathrm{~kg}$ in women and $<30 \mathrm{~kg}$ in men ${ }^{(7)}$. The between-day CV\% for handgrip strength of the dominant hand was calculated from three measurements on two separate days ( $n$ 47). The between-day CV\% was 5.0.

Furthermore, a four-metre gait speed test was conducted, which was prepared according to the protocol of the Short Physical Performance Battery (SPPB) test ${ }^{(30)}$. Subjects with gait speed $<0.8 \mathrm{~m} / \mathrm{s}$ were characterised as subjects with reduced functional performance ${ }^{(7)}$.

Subjects with reduced SMI, but with normal muscle strength and functional performance, were defined as non-sarcopenic subjects. Subjects with reduced SMI and with reduced handgrip strength and/or reduced gait speed were categorised as sarcopenic ${ }^{(7)}$.

Cognitive function was measured by the Mini-Mental State Examination (MMSE) form ${ }^{(31)}$ and the Mini Nutritional Assessment form (MNA) ${ }^{\circledR}$ was used to identify subjects with malnutrition.

\section{Plasma concentrations of amino acids and other metabolites}

Non-fasting venous blood samples were collected between 09.00 and 13.00 hours. Average time from the last meal was $2 \mathrm{~h}$ and $24 \mathrm{~min}$ among sarcopenic subjects and $2 \mathrm{~h}$ and $18 \mathrm{~min}$ among non-sarcopenic subjects. Plasma EDTA was prepared according to standardised protocols, aliquoted and frozen $\left(-80^{\circ} \mathrm{C}\right)$. NMR spectroscopy was used to quantify plasma concentrations of non-fasting amino acids (essential amino acids: leucine, valine, isoleucine, phenylalanine, tyrosine and histidine, and nonessential amino acids: alanine and glutamine), and the plasma concentrations of glycolysis-related metabolites (lactate and citrate), and ketone bodies (acetate and 3-hydroxybutyrate). The NMR platform used (Nightingale Health; www.brainshake.fi) has been applied in other human studies ${ }^{(32,33)}$, and the experimental protocol, sample preparation and spectroscopy method are described elsewhere ${ }^{(34)}$. The CV\% for the BCAA and other amino acids measured was $<3.5$ and $<10$, respectively, and $\leq 10$ and $<6$ for glycolysis-related metabolites and ketone bodies, respectively ${ }^{(35)}$. Routine serum and whole blood samples were prepared according to standardised protocols and analysed at an accredited medical laboratory (Fürst Medical Laboratory).

\section{Dietary assessment}

A dietitian performed two 24-h dietary recalls in eligible subjects using a personal computer-assisted face-to-face interview and an unannounced telephone interview after $>14 \mathrm{~d}$. Only subjects with an MMSE score $\geq 24$ (the maximal score is 30 ) were interviewed. We lack dietary data from twenty subjects with MMSE score lower than 24 points, and from eight subjects who did not complete two 24-h recall interviews owing to different reasons; for example we were not able to reach the participant for a telephone interview. The interviews were conducted in a threestep process as described in detail elsewhere ${ }^{(36)}$. Briefly, the first step involved a review of the foods and drinks consumed the previous day. Second, detailed information about the food and portion sizes was collected. The third step involved a checklist with foods and snacks that are easily forgotten, such as fruits, pastries, chocolate and dietary supplements. Food quantities were assessed by use of the Norwegian food quantification booklet with photographs of foods in different portion sizes. At the first interview, the participants received the Norwegian food quantification booklet. During the second (telephone) interview, the participants quantified the portion sizes by using the same food quantification booklet with photographs. When couples met for a visit, the partner was asked to clarify details if necessary. All 24-h recall interviews were checked for errors in coding by a second nutritionist, and the highest and lowest energy and nutrient intakes were checked for plausibility. Dietary supplements were included in the analyses. The interviews were conducted between Monday and Friday. An in-house data program (KBS version 7.0) linked to the Norwegian Food Composition Table from 2006, which was supplied with additional food items from reliable sources, was used to calculate the nutrient intake.

\section{Statistical analyses}

On the basis of previous findings in the literature, a priori power calculation was performed. We hypothesised that the correlation between protein intake and SM mass is 0.27 . With the power of $80 \%$, we need to include 105 participants to show that such a correlation is significantly higher than 0 at the significance level of $5 \%$. In order to be able to adjust the association for covariates of relevance (13 altogether) in a multiple linear regression model, 131 participants were required. The present study served as a screening visit for an RCT where a large number of subjects were assessed for eligibility (twenty-eight). Thus, the number of participants included in this cross-sectional study became larger than suggested by the power calculation.

For continuous variables, independent-samples $t$ tests and Mann-Whitney $U$ tests were used in normally distributed and not normally distributed data, respectively. For categorical variables, the $\chi^{2}$ test was used, whereas Fischer's exact test was used for small groups. All normally distributed continuous data, such as the plasma concentration of the BCAA, are presented as means (standard deviation), not normally distributed data are presented as median (interquartile range) and categorical data as count (\%). Using plasma amino acids concentrations and nutrient intakes as dependent variables, linear regression analyses were used to investigate differences between sarcopenic and non-sarcopenic subjects when adjusted for sex. Level of significance was defined as $P<0 \cdot 05$, and all tests were two-sided. All analyses were performed using SPSS for Windows (version 22.0; SPSS, Inc.).

\section{Results}

\section{Characteristics of the study population}

A total of 417 community-dwelling older women ( $n$ 218, $52 \%$ ) and men ( $n$ 199, 48\%) were included in this study. In total, $22 \%$ ( $n$ 90) of the subjects were classified as sarcopenic, and more women $(17 \%)$ than men $(5 \%)$ were sarcopenic $(P<0 \cdot 0001)$. The sarcopenic subjects were significantly older, and they were characterised by significantly lower total MMSE, MNA and SPPB 
Table 1. Characteristics of the study population

(Mean values and standard deviations; medians and 25th-75th percentiles; numbers and percentages)

\begin{tabular}{|c|c|c|c|c|c|c|c|}
\hline & \multicolumn{2}{|c|}{ Overall ( $n$ 417) } & \multicolumn{2}{|c|}{ Non-sarcopenic ( $n$ 327) } & \multicolumn{2}{|c|}{ Sarcopenic ( $n$ 90) } & \multirow[b]{2}{*}{$P$} \\
\hline & Mean $/$ median $/ n$ & $\mathrm{SD} / \mathrm{Q} 1-\mathrm{Q} 3 / \%$ & Mean $/$ median $/ n$ & $\mathrm{SD} / \mathrm{Q} 1-\mathrm{Q} 3 / \%$ & Mean/median/n & SD/Q1-Q3/\% & \\
\hline Female & 218 & 52 & 149 & 46 & 69 & 77 & \\
\hline Male & 199 & 48 & 178 & 54 & 21 & 23 & $<0.0001$ \\
\hline Age (years) & 74 & $72-78$ & 74 & $71-77$ & 78 & $74-82$ & $<0.0001$ \\
\hline Single household & 142 & 34 & 101 & 31 & 41 & 46 & 0.015 \\
\hline MMSE (score) ${ }^{\star}$ & 28 & $26-30$ & 29 & $26-30$ & 27 & $26-29$ & 0.010 \\
\hline$<24$ points & 20 & 5 & 13 & 4 & 7 & 8 & 0.16 \\
\hline MNA (score) $\dagger$ & 28 & $27-29$ & 28 & $27-29$ & 27 & $26-28$ & $<0.0001$ \\
\hline Non-malnourished & 398 & 95 & 313 & 96 & 85 & 94 & 0.38 \\
\hline Risk of malnutrition & 17 & 4 & 12 & 4 & 5 & 6 & 0.63 \\
\hline Malnourished & 0 & & 0 & & 0 & & \\
\hline SPPB (score) $\ddagger$ & 11 & $11-12$ & 12 & $11-12$ & 11 & $10-12$ & $<0.0001$ \\
\hline$\leq 8$ points & 21 & 5 & 9 & 3 & 12 & 13 & $<0.0001$ \\
\hline \multicolumn{8}{|l|}{ Co-morbid condition } \\
\hline History of CVD§ & 78 & 19 & 60 & 18 & 18 & 20 & 0.83 \\
\hline Hypertension (>140/90) & 250 & 62 & 199 & 61 & 59 & 66 & 0.49 \\
\hline Diabetest & 19 & 5 & 17 & 5 & 2 & 2 & 0.39 \\
\hline Cancert & 26 & 6 & 21 & 6 & 5 & 6 & 1.00 \\
\hline Severe inflammatory disease ${ }^{*}$ & 39 & 9 & 33 & 10 & 6 & 7 & 0.42 \\
\hline Respiratory disease $†$ & 17 & 4 & 16 & 5 & 1 & 1 & 0.14 \\
\hline Current smokert & 28 & 7 & 20 & 6 & 8 & 9 & 0.35 \\
\hline \multicolumn{8}{|l|}{ Daily use of prescriptive drug } \\
\hline None & 90 & 22 & 71 & 22 & 19 & 21 & 1.0 \\
\hline$>3$ drugs & 106 & 25 & 77 & 24 & 29 & 32 & 0.094 \\
\hline$\geq 5$ drugs & 61 & 15 & 45 & 14 & 16 & 18 & 0.34 \\
\hline \multicolumn{8}{|l|}{ Blood values } \\
\hline Serum $25-\mathrm{OH}$-vitamin $\mathrm{D}(\mathrm{nmol} / \mathrm{l})$ & $86 \cdot 8$ & $25 \cdot 3$ & $85 \cdot 3$ & $25 \cdot 1$ & 91.6 & $25 \cdot 4$ & 0.040 \\
\hline Plasma $\mathrm{Hb}(\mathrm{g} / 100 \mathrm{ml})$ & $14 \cdot 1$ & 1.1 & $14 \cdot 2$ & $1 \cdot 1$ & $13 \cdot 8$ & $1 \cdot 1$ & 0.001 \\
\hline Serum albumin $(\mathrm{g} / \mathrm{l})$ & $41 \cdot 1$ & $2 \cdot 1$ & 41.4 & $2 \cdot 2$ & $41 \cdot 3$ & 1.9 & 0.71 \\
\hline Serum total cholesterol $(\mathrm{mmol} / \mathrm{l})$ & $5 \cdot 3$ & $1 \cdot 1$ & $5 \cdot 2$ & $1 \cdot 1$ & 5.4 & 1.0 & 0.092 \\
\hline Serum LDL-cholesterol (mmol/l) & $3 \cdot 1$ & 0.9 & 3.1 & 1.0 & $3 \cdot 1$ & 1.0 & 0.93 \\
\hline Serum HDL-cholesterol (mmol/li) & 1.6 & 0.5 & 1.6 & 0.5 & 1.8 & 0.5 & $<0.0001$ \\
\hline Serum TAG $(\mathrm{mmol} / \mathrm{l}) \dagger$ & $1 \cdot 3$ & $1.0-1.9$ & 1.4 & $1.0-1.9$ & $1 \cdot 3$ & $1.0-1 \cdot 6$ & 0.089 \\
\hline Serum C-reactive protein $(\mathrm{mg} / \mathrm{l}) \|$ & 1.5 & $0.8-2 \cdot 8$ & 1.3 & $0.7-2 \cdot 7$ & 1.5 & $0.8-3 \cdot 1$ & 0.65 \\
\hline Plasma HbA1c (\%)ף & 5.9 & 0.7 & $6 \cdot 0$ & 0.8 & $5 \cdot 8$ & 0.4 & 0.095 \\
\hline
\end{tabular}

MMSE, Mini-Mental State Examination; MNA, Mini Nutritional Assessment; SPPB, Short Physical Performance Battery; 25-OD-vitamin D, 25-hydroxyvitamin D; HbA1c,

glycosylated $\mathrm{Hb}$.

* Three missing.

$\dagger$ Two missing.

$\ddagger$ Twenty-one missing.

$\S$ Twenty-three missing.

\| Thirteen missing.

If Fifteen missing.

score $(P<0 \cdot 05)$. The descriptive statistics for the study population are further outlined in Tables 1 and 2.

\section{Plasma amino acids and other metabolites}

The sarcopenic subjects had significantly lower non-fasting plasma concentration of leucine $(P<0.0001)$, isoleucine $(P=0.004)$ and valine $(P<0 \cdot 008)$ when compared with the non-sarcopenic subjects (Table 3). The non-fasting plasma concentrations of other essential and non-essential amino acids, and of glycolysis-related metabolites and ketone bodies, were similar between the groups $(P>0.05)$. After sex adjustment, non-fasting plasma concentrations of leucine and isoleucine, but not valine, remained significantly different between sarcopenic and non-sarcopenic subjects ( $P=0.003, P=0.026$ and $P=0.053$, respectively). We also investigated whether there were differences in the ratio of blood concentrations of the BCAA to BW (BCAA (mmol/l)/BW (kg)) between sarcopenic and non-sarcopenic subjects. No significant differences between the groups were observed for blood concentrations of leucine and isoleucine when adjusted for BW ( $P=0.82$ and $P=0 \cdot 24$, respectively). Valine was significantly higher among subjects with sarcopenia $(P=0 \cdot 010)$. Very strong positive correlations $(r>0.8)$ between leucine and isoleucine and valine were observed $(P<0.0001$ for both) (online Supplementary Table S1), and moderate to strong positive correlations $(0 \cdot 4<r<0 \cdot 8)$ were observed between leucine and phenylalanine, tyrosine and histidine $(P<0.0001$ for all). Finally, in a linear regression analysis where sex and leucine were included as independent variables, non-fasting leucine concentration was significantly correlating with $\mathrm{SM} /$ height $\left(\mathrm{R}=0.82, R^{2}=0.67, P<0.0001\right)$ and with handgrip strength $\left(\mathrm{R}=0 \cdot 80, R^{2}=0 \cdot 64, P=0 \cdot 030\right)$.

\section{Dietary intake}

The absolute protein intake calculated from the $2 \times 24-\mathrm{h}$ recall interview showed a significantly lower intake among 
Table 2. Anthropometry, physical strength and muscular function in sarcopenic $v$. non-sarcopenic subjects (Mean values and standard deviations; numbers and percentages)

\begin{tabular}{|c|c|c|c|c|c|c|c|c|c|c|}
\hline & \multicolumn{5}{|c|}{ Men } & \multicolumn{5}{|c|}{ Women } \\
\hline & \multirow{2}{*}{\multicolumn{2}{|c|}{$\begin{array}{c}\text { Sarcopenic } \\
(n 178)\end{array}$}} & \multirow{2}{*}{\multicolumn{2}{|c|}{$\frac{\text { Non-sarcopenic }}{(n 21)}$}} & \multirow[b]{3}{*}{$P^{\star}$} & \multirow{2}{*}{\multicolumn{2}{|c|}{$\frac{\text { Sarcopenic }}{(n 149)}$}} & \multirow{2}{*}{\multicolumn{2}{|c|}{$\frac{\text { Non-sarcopenic }}{(n 69)}$}} & \multirow[b]{3}{*}{$P+$} \\
\hline & & & & & & & & & & \\
\hline & Mean/n & $\mathrm{sD} / \%$ & Mean/n & $\mathrm{SD} / \%$ & & Mean/n & $\mathrm{sD} / \%$ & Mean/n & $\mathrm{sD} / \%$ & \\
\hline Body weight (kg) & $82 \cdot 3$ & $11 \cdot 2$ & $69 \cdot 6$ & $11 \cdot 6$ & $<0.0001$ & $71 \cdot 6$ & $13 \cdot 6$ & 63.7 & $9 \cdot 4$ & $<0.0001$ \\
\hline \multicolumn{11}{|l|}{ Weight loss in the last 3 months $\ddagger$} \\
\hline No & 153 & 86 & 17 & 81 & 0.45 & 128 & 86 & 59 & 86 & 0.94 \\
\hline$>3 \mathrm{~kg}$ & 4 & 2 & 0 & & 0.65 & 1 & 1 & 0 & & 1.0 \\
\hline Height (cm) & $177 \cdot 0$ & $6 \cdot 3$ & $172 \cdot 0$ & $6 \cdot 4$ & $<0.001$ & $163 \cdot 3$ & $6 \cdot 1$ & $160 \cdot 0$ & $5 \cdot 1$ & $<0.0001$ \\
\hline BMI $\left(\mathrm{kg} / \mathrm{m}^{2}\right)$ & $26 \cdot 3$ & 3.3 & 23.9 & $4 \cdot 1$ & 0.003 & $26 \cdot 9$ & $4 \cdot 8$ & $25 \cdot 0$ & 3.5 & 0.003 \\
\hline Fat $(\%)$ & $25 \cdot 5$ & $6 \cdot 0$ & $22 \cdot 8$ & $6 \cdot 6$ & 0.055 & 35.9 & $7 \cdot 4$ & $36 \cdot 5$ & $6 \cdot 0$ & 0.62 \\
\hline Fat mass $(\mathrm{kg})$ & $21 \cdot 4$ & $7 \cdot 1$ & $16 \cdot 3$ & $6 \cdot 7$ & 0.002 & $26 \cdot 5$ & $9 \cdot 4$ & 23.7 & $7 \cdot 0$ & 0.027 \\
\hline Fat-free mass $(\mathrm{kg})$ & $61 \cdot 0$ & $6 \cdot 6$ & $53 \cdot 3$ & $7 \cdot 1$ & $<0.0001$ & $45 \cdot 1$ & $5 \cdot 7$ & $40 \cdot 0$ & $3 \cdot 4$ & $<0.0001$ \\
\hline \multicolumn{11}{|l|}{ Variables used to define sarcopenia } \\
\hline Skeletal muscle mass index $\left(\mathrm{kg} / \mathrm{m}^{2}\right)$ & $8 \cdot 6$ & 0.8 & $8 \cdot 0$ & $1 \cdot 0$ & 0.001 & $6 \cdot 5$ & 0.9 & $5 \cdot 7$ & 0.5 & $<0.0001$ \\
\hline Maximum handgrip strength $(\mathrm{kg})$ & $39 \cdot 0$ & $6 \cdot 0$ & $25 \cdot 8$ & $5 \cdot 5$ & $<0.0001$ & 23.4 & 4.5 & $17 \cdot 1$ & $2 \cdot 2$ & $<0.0001$ \\
\hline Gait speed $(\mathrm{m} / \mathrm{s})$ & $1 \cdot 3$ & $0 \cdot 2$ & $1 \cdot 1$ & 0.3 & $<0.0001$ & $1 \cdot 3$ & $0 \cdot 2$ & $1 \cdot 2$ & 0.3 & $<0.0001$ \\
\hline
\end{tabular}

* Between sarcopenic and non-sarcopenic men.

† Between sarcopenic and non-sarcopenic women.

‡ Two missing

Table 3. Plasma concentrations (mmol/l) of amino acids

(Mean values and standard deviations)

\begin{tabular}{|c|c|c|c|c|c|c|c|c|}
\hline & \multicolumn{2}{|c|}{ Overall (n 417) } & \multicolumn{2}{|c|}{ Non-sarcopenic (n 327) } & \multicolumn{2}{|c|}{ Sarcopenic ( $n$ 90) } & \multirow[b]{2}{*}{$P^{\star}$} & \multirow[b]{2}{*}{$P+$} \\
\hline & Mean & SD & Mean & SD & Mean & SD & & \\
\hline Leu & 0.074 & 0.025 & 0.077 & 0.026 & 0.066 & 0.019 & $<0.0001$ & 0.003 \\
\hline Ile & 0.060 & 0.020 & 0.062 & 0.020 & 0.055 & 0.016 & 0.004 & 0.026 \\
\hline Val & 0.17 & 0.040 & 0.17 & 0.040 & 0.16 & 0.040 & 0.008 & 0.053 \\
\hline$\sum \mathrm{BCAA}$ & 0.31 & 0.008 & 0.31 & 0.008 & 0.28 & 0.070 & $<0.0001$ & 0.016 \\
\hline Phe & 0.067 & 0.009 & 0.068 & 0.008 & 0.066 & 0.008 & 0.16 & 0.38 \\
\hline Tyr & 0.064 & 0.017 & 0.064 & 0.017 & 0.063 & 0.018 & 0.68 & 0.51 \\
\hline Ala & 0.41 & 0.060 & 0.41 & 0.060 & 0.41 & 0.060 & 0.95 & 0.79 \\
\hline $\mathrm{His}$ & 0.048 & 0.009 & 0.048 & 0.009 & 0.046 & 0.010 & 0.13 & 0.27 \\
\hline Glx & 0.49 & 0.060 & 0.49 & 0.060 & 0.49 & 0.060 & 0.98 & 0.62 \\
\hline Lactate & 0.95 & 0.30 & 0.94 & 0.30 & 0.95 & 0.31 & 0.90 & 0.48 \\
\hline Citrate & 0.15 & 0.03 & 0.15 & 0.03 & 0.15 & 0.03 & 0.69 & 0.73 \\
\hline Acetate & 0.055 & 0.038 & 0.055 & 0.042 & 0.055 & 0.015 & 0.90 & 0.78 \\
\hline Acetoacetate & 0.037 & 0.016 & 0.036 & 0.016 & 0.037 & 0.017 & 0.63 & 0.49 \\
\hline 3-Hydroxybutyrate & 0.15 & 0.06 & 0.15 & 0.06 & 0.15 & 0.06 & 0.90 & 0.88 \\
\hline
\end{tabular}

BCAA, branched-chain amino acids.

* Between sarcopenic and non-sarcopenic subjects.

$\dagger$ Between sarcopenic and non-sarcopenic subjects when adjusted for sex.

the sarcopenic compared with non-sarcopenic subjects $(66.8$ (sD 21.4) $v .80 \cdot 3$ (sD 28.2) g proteins/d, $P<0.0001$, respectively), which remained significantly different after sex adjustments $(P=0.003)$ (Table 4). No significant difference in absolute intake of protein was observed for breakfast, lunch or dinner after sex adjustment between the two groups (Table 4). Among both sarcopenic and non-sarcopenic subjects, a significantly higher intake of protein was observed for dinner when compared with lunch and breakfast $(P<0.0001$ for all comparisons) (Table 4). When the absolute intake of protein was adjusted for BW and sex, a similar protein intake was observed between sarcopenic and non-sarcopenic subjects $(1.1 \mathrm{~g}$ protein $/ \mathrm{kg} \mathrm{BW}$ per $\mathrm{d} ; P=0.63)$. Intake of other macronutrients was similar between the two groups (Table 4), but the energy intake remained significantly lower among the sarcopenic subjects after sex adjustment $(P=0.003)$. A linear relationship was observed between energy (kJ (kcal)) intake and absolute intake of protein $(\mathrm{g} / \mathrm{d})$ when sex and sarcopenia were included in the model $\left(R=0 \cdot 68, R^{2}=0 \cdot 46\right.$, $P<0.0001)$. Intakes of micronutrients in sarcopenic and nonsarcopenic subjects are shown in the online Supplementary Table S2. After sex adjustment, intake of $\mathrm{Ca}, \mathrm{Mg}$ and $\mathrm{K}$ was significantly lower in sarcopenic compared with nonsarcopenic subjects. The intake of $\mathrm{Ca}, \mathrm{Mg}$ and $\mathrm{K}$ was significantly lower in sarcopenic and non-sarcopenic subjects when compared with dietary recommendations in older adults $^{(37)}$. Regular use of dietary supplements was reported in 83 and $74 \%$ of the sarcopenic and non-sarcopenic subjects, respectively. The most frequently used dietary supplement was cod liver oil/fish oil supplements, which were used among 
Table 4. Dietary intake from $2 \times 24-h$ recalls of the study population

\begin{tabular}{|c|c|c|c|c|c|c|c|c|}
\hline & \multicolumn{2}{|c|}{ Overall ( $n$ 389) } & \multicolumn{2}{|c|}{ Non-sarcopenic ( $n$ 307) } & \multicolumn{2}{|c|}{ Sarcopenic ( $n$ 82) } & \multirow[b]{2}{*}{$P^{\star}$} & \multirow[b]{2}{*}{$P \dagger$} \\
\hline & Mean/median & SD/Q1-Q3 & Mean/median & SD/Q1-Q3 & Mean/median & SD/Q1-Q3 & & \\
\hline Energy (MJ) & $7 \cdot 7$ & $2 \cdot 2$ & 7.9 & $2 \cdot 2$ & $6 \cdot 7$ & 1.8 & $<0.0001$ & 0.003 \\
\hline Energy (kJ/kg body weight) & 106 & $82-123$ & 103 & $82-123$ & 107 & $86-122$ & 0.66 & 0.81 \\
\hline Protein $(\mathrm{g})$ & 77 & 28 & 80 & 28 & 69 & 21 & $<0.0001$ & 0.003 \\
\hline Protein, breakfast (g) & $16 \S$ & $10-21$ & $16 \|$ & $10-21$ & $14 \pi$ & $10-21$ & 0.20 & 0.40 \\
\hline Protein, lunch $(\mathrm{g})$ & $16^{* *}$ & $12-21$ & $18+\dagger$ & $11-21$ & $16 \neq \ddagger$ & $11-21$ & 0.84 & 0.79 \\
\hline Protein, dinner $(\mathrm{g}) \ddagger$ & $35 \S \S$ & $26-46$ & 36\|\| & $24-40$ & उ2ণा & $23-41$ & 0.004 & 0.089 \\
\hline Protein ( $\mathrm{g} / \mathrm{kg}$ body weight) & 1.1 & 0.4 & 1.1 & 0.4 & 1.1 & 0.3 & 0.48 & 0.63 \\
\hline Protein (E\%) & $17 \cdot 8$ & 4.3 & 17.9 & 4.4 & $17 \cdot 4$ & 4.0 & 0.38 & 0.41 \\
\hline Total fat (E\%) & $38 \cdot 3$ & $7 \cdot 8$ & 38.2 & 8.0 & 38.6 & $6 \cdot 8$ & 0.67 & 0.95 \\
\hline Saturated fat (E\%) & $15 \cdot 0$ & 4.2 & 14.8 & $4 \cdot 2$ & $15 \cdot 6$ & 3.9 & 0.16 & 0.39 \\
\hline Polyunsaturated fat (E\%) & $6 \cdot 7$ & $2 \cdot 4$ & $6 \cdot 7$ & $2 \cdot 3$ & 6.5 & $2 \cdot 4$ & 0.35 & 0.47 \\
\hline Monounsaturated fat (E\%) & $12 \cdot 7$ & $3 \cdot 2$ & $12 \cdot 7$ & 3.3 & $12 \cdot 7$ & $2 \cdot 7$ & 0.95 & 0.78 \\
\hline Carbohydrates (E\%) & $40 \cdot 3$ & 7.8 & $40 \cdot 1$ & 8.0 & $40 \cdot 9$ & $7 \cdot 1$ & 0.43 & 0.22 \\
\hline Added sugar (E\%) & 6.6 & 4.0 & 6.5 & 4.0 & 6.8 & 3.7 & 0.61 & 0.46 \\
\hline Fibre $(E \%)$ & $2 \cdot 2$ & 0.7 & $2 \cdot 2$ & 0.7 & $2 \cdot 3$ & 0.8 & 0.10 & 0.23 \\
\hline Fibre $(\mathrm{g})$ & $20 \cdot 0$ & 7.5 & $20 \cdot 4$ & 7.4 & 18.5 & $7 \cdot 8$ & 0.044 & 0.22 \\
\hline Alcohol $(\mathrm{E} \%)^{\star \star \star}$ & 2.5 & $0.0-3.4$ & 0.0 & $0.0-3.7$ & 0.0 & $0.0-0.0$ & 0.15 & 0.15 \\
\hline
\end{tabular}

* Between sarcopenic and non-sarcopenic subjects.

† Between sarcopenic and non-sarcopenic subjects when adjusted for sex.

$\ddagger$ Within-group comparisons between dinner $v$. lunch and dinner $v$. breakfast $(P<0.001$ for all comparisons).

$\S n 369$.

II $n 294$

I $n 74$.

** $n 235$.

†† $n 194$.

㧊 $n 44$.

$\S \S n 369$.

|| $n 271$.

ๆी $n 67$.

${ }_{\star \star \star} n 161$ subjects reported intake of alcohol (128 among the non-sarcopenic and thirty-three among the sarcopenic subjects).

68 and $57 \%$ of the sarcopenic and non-sarcopenic subjects, respectively.

\section{Discussion}

In the present study, we observed that sarcopenia among community-dwelling older adults, characterised by the EWGSOP criteria, is associated with lower non-fasting plasma concentrations of the BCAA leucine and isoleucine, and a lower absolute intake of protein compared with non-sarcopenic subjects. This study suggests that postprandial amino acids kinetics and metabolism should be further investigated to elucidate the clinical relevance of lower non-fasting plasma concentrations of BCAA in sarcopenic older adults.

In a cross-over study in healthy adult men, intake of a high $v$. normal protein meal in the evening ( $116 \mathrm{~g}$ of protein, 40 of energy intake (E\%) v. $35 \mathrm{~g}$ of protein, $15 \% \mathrm{E} \%$, respectively) showed an increased plasma concentration of BCAA the next morning, $12 \mathrm{~h}$ after intake ${ }^{(15)}$. Postprandial plasma concentrations of amino acids (including leucine) and basal muscle protein synthesis response were similar over $5 \mathrm{~h}$ in healthy older men (approximately 62 years) after intake of $25 \mathrm{~g}$ of whey protein, where a habitual low $v$. high protein intake $(0.7 v .1 .5 \mathrm{~g}$ protein/kg BW per $\mathrm{d}$, respectively) was followed for $14 \mathrm{~d}$ in advance of the test meal ${ }^{(38)}$. The authors suggest reduced postprandial splanchnic amino acid retention in subjects with low habitual protein intake ${ }^{(38)}$. This is in line with findings in previous studies that have suggested that essential amino acids can be retained in the gut, and temporarily stored ${ }^{(12,20,39)}$. In the present study, the total daily amount of protein was significantly lower among the sarcopenic subjects. Whether a lower daily intake of protein over time leads to lower non-fasting plasma concentration of the BCAA, in particular, needs to be further investigated. In addition, we are unable to elucidate whether the plasma concentration of BCAA could be related to protein intake in certain meals. However, prospective long-term followup studies have shown that older adults have reduced ability to maintain muscle mass and functional performance from a low protein intake, similar to $\leq 0.8 \mathrm{~g} / \mathrm{kg}$ BW per $\mathrm{d}^{(6,11,40)}$. Non-fasting plasma concentrations of amino acids from longterm intake of low $v$. high protein intake need to be further investigated, with net anabolic response and/or the muscle mass maintenance included as end points. The present crosssectional study shows that sarcopenic subjects have lower nonfasting plasma concentrations of amino acids that are highly relevant in the prevention of sarcopenia. We also show very strong correlations between leucine and both isoleucine and valine, and between leucine and both SMI (adjusted for height) and maximum handgrip strength (dominant hand). Whether plasma concentrations of BCAA, and especially of leucine, are potential biomarkers of sarcopenia, providing useful information beyond dietary assessments, needs further investigation. At present, no optimal or minimum plasma concentrations of the BCAA required for maintenance of SM mass have been defined. Increased plasma and intramuscular concentration of leucine, in particular, stimulates the muscle protein synthesis by activation of the mammalian target of rapamycin (mTOR) signalling 
pathway, as well as decreasing muscle protein breakdown $^{(17,19,21)}$. Older adults may be less responsive to activation of the mTOR signalling pathway by amino acids than younger adults (anabolic resistance) ${ }^{(41-43)}$. Thus, higher protein intake has been suggested to be necessary to maximally stimulate postprandial muscle protein synthesis in order to slow or prevent sarcopenia in older adults ${ }^{(37)}$. Hence, the clinical relevance of the significantly lower plasma concentrations of the BCAA and leucine in particular, in relation prevention of sarcopenia, needs further investigations.

A higher protein intake has been recommended in older $v$. younger adults to maximally stimulate postprandial muscle protein synthesis and prevent sarcopenia ${ }^{(7,20,22,23,37,44,45)}$. Our results corroborate with previous findings in sarcopenic and frail older adults, showing significantly lower absolute intake of protein when compared with non-sarcopenic and non-frail older adults ${ }^{(4,9,27,46)}$. However, when adjusting absolute intake of protein for BW, we and others show that sarcopenic and frail older adults have a protein intake in accordance with the dietary recommendation $(9,10,26,27,40,46-48)$. We also show that subjects with sarcopenia have lower plasma concentration of leucine and isoleucine, but similar concentrations to nonsarcopenic subjects when adjusting for BW. When adjusting for BW, subjects with lower BW (e.g. sarcopenic subjects) have increased likelihood of an adequate protein intake and to obtain similar blood concentration of essential amino acids as non-sarcopenic subjects. If the plasma concentration of leucine is important in order to dictate the amplitude of the muscle anabolic response to protein ingestion, adjusting with BW might not be an appropriate approach. Further, when adjusting protein intake for BW, the protein intake on individual- and not group-aggregated level was used. Thus, these results need to be interpreted with caution. Because of the study design, we are not able to conclude whether there is a cause-effect relationship between the self-reported protein intake and the plasma concentrations of amino acids, or between SM mass and energy and absolute protein intake over time.

Sex adjustment did not reveal differences in the protein intake for breakfast, lunch or dinner between the sarcopenic and non-sarcopenic older adults. However, a significantly higher protein intake for dinner, compared with lunch and breakfast, was observed in both groups. Protein intake pattern has been suggested to be advantageous in older adults for optimal muscle protein synthesis ${ }^{(49)}$, and lower protein intake $(<20 \mathrm{~g} / \mathrm{meal})$ has shown reduced muscle protein synthesis in older $v$. younger subjects ${ }^{(23)}$. However, the evidence for a more beneficial effect from the protein intake pattern than the total daily protein intake on the net anabolic response and maintenance of SM mass seems to be lacking ${ }^{(22,45,50)}$

Previous studies comparing dietary intakes in sarcopenic and non-sarcopenic adults ( $\geq 65$ years) suggest lower dietary intakes of protein, $n-3$ fatty acids, folic acid, vitamin $\mathrm{B}_{6}$, vitamin $\mathrm{E}$ and $\mathrm{Mg}$ in sarcopenic adults ${ }^{(9,10)}$. If energy intake is insufficient, proteins are being used in gluconeogenesis to produce glucose, and increased muscle protein breakdown may occur. However, we were not able to reveal any difference in selfreported weight loss in the last 3 months or in blood concentration of glycolysis-related metabolites and ketone bodies between sarcopenic and non-sarcopenic subjects. However, changes may have occurred over time, which we are unable to detect in the current study. The lower intakes of micronutrients among the sarcopenic subjects in the present study $(\mathrm{Ca}, \mathrm{Na}, \mathrm{K}$ and $\mathrm{Mg}$ ) are most likely caused by the lower food intake among the sarcopenic subjects. The lower intakes in both groups of $\mathrm{Ca}, \mathrm{Mg}$ and $\mathrm{K}$ than recommended intake for older adults ( $\geq 65$ years) may suggest that that the diet is not adequate in older adults. Another explanation could be under-reporting. Because of high intraindividual variability on dietary intake, it has been suggested that subjects should record 24-h recall consumption for at least $3 \mathrm{~d}$ in order to obtain data at the individual level ${ }^{(51)}$. Although a valid dietary method was used to assess the dietary intake, the aggregated data at the group level are not suitable for correcting for misreporting, which demands energy intake at an individual level. Thus, in our study, we were unfortunately not able to correct for under-reporting.

There are some limitations in the present study. Non-fasting measurement of amino acids might reflect the amino acid metabolism, but it is equally plausible that it reflects the content of protein in the last meal or the time since their last meal. However, the time from the last meal was similar between sarcopenic and non-sarcopenic subjects. Because the blood samples were drawn early in the morning and latest 13.00 hours, we assume that few persons had the main meal with a large amount of protein before the blood samples. Unfortunately, we did not collect information about which meals they had eaten before the blood sample. Further, the reliability of using one non-fasting blood sample for measuring amino acids and metabolites may be questioned. Data from the European Prospective Investigation into Cancer and Nutrition (EPIC) study have shown that the reliability of amino acids over a 2-year period did not differ according to fasting status, but weaker reliability over time was observed in some amino acids, including the $\mathrm{BCAA}^{(52)}$. More studies are therefore needed to conclude. In most studies, no relationship between sex and sarcopenia prevalence has been suggested ${ }^{(53)}$. The prevalence of sarcopenia in the present study is affected by the methods used and the cut-offs made by the EWGSOP, but we are not able to explain why more women than men were diagnosed with sarcopenia in the present study. Since men contributed less with their characteristics in the common estimate for those with sarcopenia, sex adjustment was performed when searching for differences between sarcopenic and non-sarcopenic subjects. The low response rate (17\%) could under- or over-estimate the prevalence of sarcopenia in the present study, but this may not necessarily lead to a biased relationship between variables, such as the very strong relationship observed between leucine and the SMI and handgrip strength. Unfortunately, we have no standardised information to report on daily physical activity level. The present study had a much larger sample size than calculated a priori. As the absolute number of sarcopenic subjects included is affected by the prevalence of sarcopenia, the larger sample size is a major strength. A lager sample size also made it possible to detect small differences in plasma BCAA concentrations between sarcopenic and non-sarcopenic subjects. Further investigation is needed to determine the clinical relevance of the differences. 
This present study shows that sarcopenic older adults have a lower absolute intake of protein and lower non-fasting plasma concentrations of leucine and isoleucine, when compared with non-sarcopenic subjects. By adjusting for BW, the protein intake is similar and adequate in both groups. More studies are needed to define the optimal plasma levels of BCAA in relation to maintenance of muscle mass and prevention of sarcopenia. Whether the plasma concentrations of BCAA have a potential as biomarkers of sarcopenia should be further investigated.

\section{Acknowledgements}

The authors gratefully acknowledge the participants who volunteered in this study, and the authors thank Ellen Raael, Marit Sandvik, Kristin Torvik and Nima Wesseltoft-Rao for valuable assistance in this project.

The present study was supported by the Research Council of Norway (grant no. 225258/E40), Oslo and Akershus University College of Applied Sciences, University of Oslo, Throne Holst Foundation for Nutrition Research and TINE SA. During the past 5 years, S. M. U. has received research grants from Mills DA and Olympic Seafood, none of which are related to the content of this manuscript. During the past 5 years, K. B. H. has received research grants or honoraria from Mills DA, Olympic Seafood, Amgen, Sanofi and Pronova, none of which are related to the contents of this manuscript. The Research Council of Norway had no role in the design, analysis or writing of this article.

I. O., S. M. U., L. F. A., G. O. G., A. S. B. and K. B. H. conceived and designed the study; I. O., L. K. L. Ø., N. A. S., K. S. S. and A. B. conducted the research; I. O., S. M. U. and K. B. H. interpreted and performed statistical analyses; and I. O., S. M. U. and K. B. H. wrote the paper and had the primary responsibility for final content. All authors have critically reviewed the manuscript.

G. O. G. and A. S. B. are researchers employed in TINE SA, Oslo, Norway. They have no financial interest to declare. I. O., L. K. L. Ø., K. S. S., A. B., N. A. S. and L. F. A. have no conflicts of interest.

\section{Supplementary material}

For supplementary material/s referred to in this article, please visit https://doi.org/10.1017/S0007114518001307

\section{References}

1. Guralnik JM, Simonsick EM, Ferrucci L, et al. (1994) A short physical performance battery assessing lower extremity function: association with self-reported disability and prediction of mortality and nursing home admission. J Gerontol 49, M85-M94.

2. Newman AB, Kupelian V, Visser M, et al. (2006) Strength, but not muscle mass, is associated with mortality in the health, aging and body composition study cohort. J Gerontol A Biol Sci Med Sci 61, 72-77.

3. Batsis JA, Mackenzie TA, Barre LK, et al. (2014) Sarcopenia, sarcopenic obesity and mortality in older adults: results from the National Health and Nutrition Examination Survey III. Eur J Clin Nutr 68, 1001-1007.

4. Verlaan S, Aspray TJ, Bauer JM, et al. (2017) Nutritional status, body composition, and quality of life in community-dwelling sarcopenic and non-sarcopenic older adults: a case-control study. Clin Nutr 36, 267-274.
5. Beaudart C, Reginster JY, Petermans J, et al. (2015) Quality of life and physical components linked to sarcopenia: the SarcoPhAge study. Exp Gerontol 69, 103-110.

6. Houston DK, Nicklas BJ, Ding J, et al. (2008) Dietary protein intake is associated with lean mass change in older, community-dwelling adults: the Health, Aging, and Body Composition (Health ABC) Study. Am J Clin Nutr 87, 150-155.

7. Cruz-Jentoft AJ, Baeyens JP, Bauer JM, et al. (2010) Sarcopenia: European consensus on definition and diagnosis: report of the European Working Group on Sarcopenia in Older People. Age Ageing 39, 412-423.

8. Deutz NE, Bauer JM, Barazzoni R, et al. (2014) Protein intake and exercise for optimal muscle function with aging: recommendations from the ESPEN Expert Group. Clin Nutr 33, 929-936.

9. Ter Borg S, de Groot LC, Mijnarends DM, et al. (2016) Differences in nutrient intake and biochemical nutrient status between sarcopenic and nonsarcopenic older adults - results from The Maastricht Sarcopenia Study. J Am Med Dir Assoc 17, 393-401.

10. Oh C, Jeon BH, Reid Storm SN, et al. (2017) The most effective factors to offset sarcopenia and obesity in the older Korean: Physical activity, vitamin D, and protein intake. Nutrition $\mathbf{3 3}$, $169-173$.

11. Isanejad M, Mursu J, Sirola J, et al. (2016) Dietary protein intake is associated with better physical function and muscle strength among elderly women. Br J Nutr 115, 1281-1291.

12. Wahren J, Felig P \& Hagenfeldt L (1976) Effect of protein ingestion on splanchnic and leg metabolism in normal man and in patients with diabetes mellitus. J Clin Invest 57, 987-999.

13. Elia M \& Livesey G (1983) Effects of ingested steak and infused leucine on forelimb metabolism in man and the fate of the carbon skeletons and amino groups of branched-chain amino acids. Clin Sci 64, 517-526.

14. Brosnan JT \& Brosnan ME (2006) Branched-chain amino acids: enzyme and substrate regulation. J Nutr $\mathbf{1 3 6}$, 207s-211s.

15. Nishioka M, Imaizumi A, Ando T, et al. (2013) The overnight effect of dietary energy balance on postprandial plasma free amino acid (PFAA) profiles in Japanese adult men. PLOS ONE 8, e62929.

16. Forslund AH, El-Khoury AE, Olsson RM, et al. (1999) Effect of protein intake and physical activity on 24-h pattern and rate of macronutrient utilization. Am J Physiol 276, E964-E976.

17. Bohe J, Low A, Wolfe RR, et al. (2003) Human muscle protein synthesis is modulated by extracellular, not intramuscular amino acid availability: a dose-response study. J Physiol $\mathbf{5 5 2}$, 315-324.

18. Atherton PJ, Smith K, Etheridge T, et al. (2010) Distinct anabolic signalling responses to amino acids in $\mathrm{C} 2 \mathrm{C} 12$ skeletal muscle cells. Amino Acids 38, 1533-1539.

19. Pasiakos SM \& McClung JP (2011) Supplemental dietary leucine and the skeletal muscle anabolic response to essential amino acids. Nutr Rev 69, 550-557.

20. Deutz NE \& Wolfe RR (2013) Is there a maximal anabolic response to protein intake with a meal? Clin Nutr 32, 309-313.

21. Kim IY, Schutzler S, Schrader A, et al. (2016) The anabolic response to a meal containing different amounts of protein is not limited by the maximal stimulation of protein synthesis in healthy young adults. I Physiol Endocrinol Metab 310, E73-E80.

22. Baum JI, Kim IY \& Wolfe RR (2016) Protein consumption and the elderly: what is the optimal level of intake? Nutrients $8,6$.

23. Cuthbertson D, Smith K, Babraj J, et al. (2005) Anabolic signaling deficits underlie amino acid resistance of wasting, aging muscle. FASEB J 19, 422-424. 
24. Wolfe RR (2012) The role of dietary protein in optimizing muscle mass, function and health outcomes in older individuals. Br J Nutr 108, Suppl. 2, S88-S93.

25. Lustgarten MS, Price LL, Chale A, et al. (2014) Branched chain amino acids are associated with muscle mass in functionally limited older adults. Gerontology A Biol Sci Med Sci 69, $717-724$.

26. ter Borg S, Verlaan S, Mijnarends DM, et al. (2015) Macronutrient intake and inadequacies of community-dwelling older adults, a systematic review. Ann Nutr Metab 66, 242-255.

27. Park S, Ham JO \& Lee BK (2014) A positive association of vitamin D deficiency and sarcopenia in 50 year old women, but not men. Clin Nutr 33, 900-905.

28. Ottestad I (2017) Intake of a protein-enriched milk and effects on muscle mass and strength. A 12-week randomized placebo controlled trial among community-dwelling older adults. J Nutr Health Aging 21, 1160-1169.

29. Janssen I, Heymsfield SB, Baumgartner RN, et al. (2000) Estimation of skeletal muscle mass by bioelectrical impedance analysis. J Appl Physiol 89, 465-471.

30. Cavazzini C, Conti M, Bandinelli S, et al. (2004) Screening for poor performance of lower extremity in primary care: the Camucia Project. Aging Clin Exp Res 16, 331-336.

31. Tombaugh TN \& McIntyre NJ (1992) The mini-mental state examination: a comprehensive review. J Am Geriatr Soc $\mathbf{4 0}$, 922-935.

32. Fischer K, Kettunen J, Wurtz P, et al. (2014) Biomarker profiling by nuclear magnetic resonance spectroscopy for the prediction of all-cause mortality: an observational study of 17,345 persons. PLoS Med 11, e1001606.

33. Inouye M, Kettunen J, Soininen P, et al. (2010) Metabonomic, transcriptomic, and genomic variation of a population cohort. Mol Syst Biol 6, 441

34. Soininen P, Kangas AJ, Wurtz P, et al. (2009) High-throughput serum NMR metabonomics for cost-effective holistic studies on systemic metabolism. Analyst 134, 1781-1785.

35. Kettunen J, Demirkan A, Wurtz P, et al. (2016) Genome-wide study for circulating metabolites identifies 62 loci and reveals novel systemic effects of LPA. Nat Commun 7, 11122

36. Myhre JB, Loken EB, Wandel M, et al. (2015) The contribution of snacks to dietary intake and their association with eating location among Norwegian adults - results from a crosssectional dietary survey. BMC Public Health 15, 369.

37. Nordic Council of Ministers \& Nordic Nutrition Recommendations (2012) Intergrating Nutrition and Physical Activity, 5th ed. Nord 2014:02. Copenhagen: Nordic Council of Ministers \& Nordic Nutrition Recommendations.

38. Gorissen SH, Horstman AM, Franssen R, et al. (2017) Habituation to low or high protein intake does not modulate basal or postprandial muscle protein synthesis rates: a randomized trial. Am J Clin Nutr 105, 332-342.
39. Soeters PB, de Jong CH \& Deutz NE (2001) The protein sparing function of the gut and the quality of food protein. Clin Nutr 20, 97-99.

40. Meng X, Zhu K, Devine A, et al. (2009) A 5-year cohort study of the effects of high protein intake on lean mass and BMC in elderly postmenopausal women. J Bone Miner Res 24, 1827-1834.

41. Katsanos CS, Kobayashi H, Sheffield-Moore M, et al. (2005) Aging is associated with diminished accretion of muscle proteins after the ingestion of a small bolus of essential amino acids. Am J Clin Nutr 82, 1065-1073.

42. Moore DR, Churchward-Venne TA, Witard O, et al. (2015) Protein ingestion to stimulate myofibrillar protein synthesis requires greater relative protein intakes in healthy older versus younger men. Gerontology A Biol Sci Med Sci 70, 57-62.

43. Paddon-Jones D, Sheffield-Moore M, Zhang XJ, et al. (2004) Amino acid ingestion improves muscle protein synthesis in the young and elderly. J Physiol Endocrinol Metab 286, E321-E328.

44. Paddon-Jones D \& Rasmussen BB (2009) Dietary protein recommendations and the prevention of sarcopenia. Curr Opin Clin Nutr Metab Care 12, 86-90.

45. Bauer J, Biolo G, Cederholm T, et al. (2013) Evidence-based recommendations for optimal dietary protein intake in older people: a position paper from the PROT-AGE Study Group. J Am Med Dir Assoc 14, 542-559.

46. Tieland $\mathrm{M}$, Borgonjen-Van den Berg KJ, van Loon LJ, et al. (2012) Dietary protein intake in community-dwelling, frail, and institutionalized elderly people: scope for improvement. Eur J Nutr 51, 173-179.

47. Tieland M, Borgonjen-Van den Berg KJ, Van Loon LJ, et al. (2015) Dietary protein intake in dutch elderly people: a focus on protein sources. Nutrients 7, 9697-9706.

48. Mendonca N, Hill TR, Granic A, et al. (2016) Macronutrient intake and food sources in the very old: analysis of the Newcastle 85+ Study. Br J Nutr 115, 2170-2180.

49. Mamerow MM, Mettler JA, English KL, et al. (2014) Dietary protein distribution positively influences 24 -h muscle protein synthesis in healthy adults. J Nutr 144, 876-880.

50. Kim IY, Schutzler S, Schrader A, et al. (2015) Quantity of dietary protein intake, but not pattern of intake, affects net protein balance primarily through differences in protein synthesis in older adults. J Physiol Endocrinol Metab 308, E21-E28.

51. European Food Safety Authority (2009) General principles for the collection of national food consumption data in the view of a pan-European dietary survey. EFSA J 7, 1435.

52. Carayol M, Licaj I, Achaintre D, et al. (2015) Reliability of serum metabolites over a two-year period: a targeted metabolomic approach in fasting and non-fasting samples from EPIC. PLOS ONE 10, e0135437.

53. Cruz-Jentoft AJ, Landi F, Schneider SM, et al. (2014) Prevalence of and interventions for sarcopenia in ageing adults: a systematic review. Report of the International Sarcopenia Initiative (EWGSOP and IWGS). Age Ageing 43, 748-759. 